\title{
Assessing the Outcome of Adult Kidney Transplantation from a Deceased Expanded Criteria Donor: A Descriptive Study
}

Mona Alshahrani ${ }^{1}$, Mutlaq Alotaibi ${ }^{1}$, Burhan Bhutto ${ }^{1}$

1. Nephrology, McMaster University, Hamilton, CAN

Corresponding author: Mona Alshahrani, mona.alshahrani@medportal.ca

\section{Abstract \\ Background}

End-stage renal disease (ESRD) creates a great burden on the quality of life. Patients after kidney transplantation have been reported to have a greater quality of life and better outcomes health outcomes. Therefore, it is important to optimize the best method of following well-constructed criteria such as the expanded criteria donor (ECD) to reduce the chances of rejection rate and deaths post-transplantation particularly in elderly patients in conjunction with the kidney profile donor index (KDPI).

\section{Methods}

This is a retrospective descriptive study of all patients who received kidney transplantation from a deceased donor from the ECD as well as ECD with donation after cardiac death (DCD) at St. Joseph Health Care Hospital over a 24 month time period from January 2017 to January 2019. All adult recipients from standard criteria donor (SCD) and living donors were excluded from the study.

\section{Results}

The study included 60 patients with 36 (60\%) from the ECD and 24 (40\%) were from the ECD/DCD group. The most common cause of ESRD among recipients was diabetes mellitus (DM) involving 23 (38.3\%) of the patients. The creatinine outcome was the highest in the ECD/DCD group at one month $(211 \pm 71)$ and the lowest creatinine recorded was also in the ECD/DCD at 12 months ( $160 \pm 78$ ). Lastly, only four patients died in 12 months and only six recipients reported graft loss over 12 months.

\section{Conclusion}

Descriptive data of the included ECD/DCD showed increase trend in survivability of the recipients when used among the elderly, giving us more insight on the benefits of ECD/DCD transplantation.

Review began 09/10/2020 Review ended 10/20/2020 Published 10/27/2020

\section{() Copyright 2020}

Alshahrani et al. This is an open access article distributed under the terms of the Creative Commons Attribution License CC-BY 4.0., which permits unrestricted use, distribution, and reproduction in any medium, provided the original author and source are credited.
Categories: Nephrology, Transplantation

Keywords: outcome, expanded criteria donor, transplantation, kidney donor profile index

\section{Introduction}

Kidney transplantation proves to be the best treatment of choice for most patients with end-stage renal disease (ESRD). Generally, survival and quality of life are found to be superior in allograft recipients compared with patients on the deceased donor waitlist [1]. This benefit is also observed among recipients over the age of 60 years with a relatively beneficial noticeable reduced risk of cardiovascular events $[2,3]$. Moreover, there is a large gap between the number of patients waiting for a transplant and the number receiving a transplant, which leads to a renewed interest in the use of expanded criteria donor (ECD) kidneys to increase the donor pool particularly for the elderly recipients $[4,5]$.

The Organ Procurement and Transplantation Network (OPTN) instituted a formalized definition of marginal kidneys in 2002 with the advent of ECD [5]. According to Metzger et al., ECD kidneys are those either from a deceased donor $\geqslant 60$ years of age, or a donor 50 to 59 years of age with at least two of the following features: history of hypertension, terminal serum creatinine $>1.5 \mathrm{mg} / \mathrm{dL}(133 \mathrm{mmol} / \mathrm{L})$, or cerebrovascular cause of death [5]. Such criteria were defined based on the presence of variables that had an increased risk of graft failure by $70 \%$ in comparison with the standard criteria donor kidney (SCD) [5]. Allocation policies from the United Network for Organ Sharing (UNOS) require those who are on the transplantation waiting list to be given the choice to be included in the ECD kidneys and those who are included in that list are eligible to receive SCD kidneys as well [6].

Studies suggest that kidneys from donors over the age of 60 may have suboptimal graft survival, with a three-year graft survival being only 58\% [7] while a recent study suggests that the new age of worsening 
survival rate has increased to 70 years of age in the same group [8]. Therefore, the donor age is thought to be the most significant factor that can negatively impact graft survival [9]. The kidney profile donor index (KDPI) score has been used to assess the risk of graft loss of any given donor compared to the median population of donors using 10 donor-specific criteria including age, sex, height, weight, history, and duration of hypertension and diabetes, hepatitis C virus (HCV) status, donation after cardiac death (DCD) status, and donor cause of death. Therefore, the KDPI index has been used to identify organs that may have decreased survival compared to the SCD groups, and scores of $>=85$ are thought to be associated with poorer long-term allograft survival [10]. A donor kidney with a KDPI score of $\geqslant 85$ has been characterized in the literature as having similar donor characteristics as an ECD kidney [11]. Traditionally, donor kidneys that were classified as ECD have been shown to have decreased allograft survival compared to SCD kidneys. By 2006, most Canadian organ procurement organizations, including Ontario's Trillium Gift of Life Network (TGLN) started using the ECD classification to allocate deceased donor kidneys. Despite the increasing use of ECD kidneys for transplantation, the outcomes of kidneys from deceased donors with ECD characteristics has received little attention in literature. For this reason, we conducted this study to assess the kidney transplant outcome from ECD donors at St. Joseph Health Care Hamilton, Ontario, Canada, and is the first study to be conducted in our center.

\section{Materials And Methods \\ Patients}

We included in this retrospective descriptive study all adult renal transplant recipients who received a deceased donor kidney from an ECD from January 2017 to January 2019 at St. Joseph Health Hamilton, Ontario in Canada. We excluded the living kidney transplant recipients, non-ECD donors, and KDPI that cannot be calculated based on the donor information available. The study protocol was approved by the Hamilton Integrated Research Ethics Board. Data was collected from Ontario’s Trillium Gift of Life Network (TGLN) donor charts and recipients' charts in the St. Joseph Health Care System using Epic (Epic Systems Corporation, Verona, WI, USA).

\section{Study population}

A total of 60 adult recipients (age $\geqslant 18$ years) who received an ECD kidney transplant from January 2017 to January 2019 were eligible for the study including those with a prior kidney transplant and ECD/DCD donors. Adult recipients from SCD and living donors were excluded from the study.

\section{Outcomes}

The primary outcomes were renal function at 12 months measured by serum creatinine, total graft loss defined as the time from transplantation to a composite of return to chronic dialysis, pre-emptive retransplant or death with graft function, all-causes of mortality, and primary nonfunction graft which was defined as a failed function of the transplanted kidney that necessitated continued maintenance dialysis. The secondary outcomes were incidence of delay graft function (DGF) defined as kidney function that ultimately supported the patient but necessitated post-transplantation dialysis within seven days after kidney transplant, biopsy-proven allograft rejection, the incidence of cytomegalovirus (CMV), and BK virus (BKV) in the first 12 months after the kidney transplant and length of stay in the hospital after the transplant.

\section{Results}

Out of the 60 patients, 36 (60\%) belonged to the ECD while 24 (40\%) belonged to the ECD and DCD group. Regarding age, the mean age of the recipient group was $68 \pm 7.6$ years while the mean age of the donor was $62 \pm 4.8$ years. In addition, the mean body mass index (BMI) of the recipients and donors was $28 \pm 6$ years and $29.4 \pm 6.8$ years, respectively. As well, 23 recipients (38.3\%) had diabetes mellitus (DM) as the cause of ESRD making it the most common cause, followed by glomerulonephritis with 15 reported cause (25\%), and the least common cause was polycystic kidney disease in three patients (5\%). Most recipients had hemodialysis at baseline therapy 43 (71.7\%) compared to only 15 (25\%) towards peritoneal dialysis and two (3.3\%) patients with a failed kidney transplantation. Regarding the choice of an induction agent, 46 (76.6\%) patients received basiliximab alone, 11 (18.3\%) recipients received anti-thymocyte globulin (ATG), and only $3(5 \%)$ received both (Table 1 ).

\section{Baseline Recipient characteristics}




\section{Cureus}

\begin{tabular}{|c|c|c|c|c|c|c|c|}
\hline \multicolumn{2}{|l|}{ BMI mean \pm SD } & \multicolumn{2}{|c|}{$28 \pm 6$} & \multicolumn{2}{|c|}{$27 \pm 6$} & \multicolumn{2}{|c|}{$27.8 \pm 6$} \\
\hline \multirow{2}{*}{ Sex } & Male & 40 & $66.7 \%$ & 22 & $61 \%$ & 18 & $75 \%$ \\
\hline & Female & 20 & $33.3 \%$ & 14 & $39 \%$ & 6 & $25 \%$ \\
\hline \multirow{6}{*}{ Cause of ESRD } & Diabetes mellitus & 23 & $38.3 \%$ & 12 & $33.3 \%$ & 11 & $45 \%$ \\
\hline & Hypertension/Reno-vascular Disease & 8 & $13.3 \%$ & 7 & $19.4 \%$ & 1 & 4.2 \\
\hline & Polycystic Kidney Disease & 3 & $5 \%$ & 1 & $2.8 \%$ & 2 & $8.3 \%$ \\
\hline & Glomerulonephritis & 15 & $25 \%$ & 7 & $19.4 \%$ & 8 & $33.3 \%$ \\
\hline & Other & 10 & $16.6 \%$ & 8 & $22.2 \%$ & 2 & $8.3 \%$ \\
\hline & Unknown & 1 & $1.7 \%$ & 1 & $2.8 \%$ & 0 & $0 \%$ \\
\hline \multirow{3}{*}{ Renal replacement therapy at baseline } & Failed Kidney Transplant & 2 & $3.3 \%$ & 2 & $5.6 \%$ & 0 & $0 \%$ \\
\hline & Hemodialysis & 43 & $71.7 \%$ & 26 & $72.2 \%$ & 17 & $71 \%$ \\
\hline & Peritoneal Dialysis & 15 & $25 \%$ & 8 & $22.2 \%$ & 7 & $29 \%$ \\
\hline \multirow{2}{*}{ Number of transplant } & First & 56 & $93.3 \%$ & 32 & $88.9 \%$ & 24 & $100 \%$ \\
\hline & Second & 4 & $6.7 \%$ & 4 & $11.1 \%$ & 0 & $0 \%$ \\
\hline \multirow{3}{*}{ Induction } & Basilixmab & 46 & $76.7 \%$ & 28 & $77.8 \%$ & 18 & $75 \%$ \\
\hline & Anti-thymocyte globulin & 11 & $18.3 \%$ & 8 & $22.2 \%$ & 3 & $12.5 \%$ \\
\hline & Both & 3 & $5 \%$ & 0 & $0 \%$ & 3 & $12.5 \%$ \\
\hline \multirow{4}{*}{ HLA-DR Match } & 0 Match & 40 & $66.7 \%$ & 24 & $64.9 \%$ & 16 & $66.7 \%$ \\
\hline & 1 Match & 17 & $28.3 \%$ & 10 & $27 \%$ & 7 & $29.2 \%$ \\
\hline & 2 Match & 3 & $5 \%$ & 2 & $5.4 \%$ & 1 & $4.2 \%$ \\
\hline & Unknown & 1 & $1.7 \%$ & 1 & $2.7 \%$ & 0 & $0 \%$ \\
\hline \multirow{4}{*}{ HLA-DQ Match } & 0 Match & 28 & $46.7 \%$ & 17 & $45.9 \%$ & 11 & $44 \%$ \\
\hline & 1 Match & 27 & $45 \%$ & 16 & $43.2 \%$ & 11 & $44 \%$ \\
\hline & 2 Match & 6 & $10 \%$ & 3 & $8.1 \%$ & 3 & $12 \%$ \\
\hline & Unknown & 1 & $1.7 \%$ & 1 & $2.7 \%$ & 0 & $0 \%$ \\
\hline \multirow{4}{*}{ Warm ischemia (Minutes) } & Mean & \multicolumn{2}{|c|}{38 Minute } & \multicolumn{2}{|c|}{38 Minute } & \multicolumn{2}{|c|}{38 Minute } \\
\hline & SD & \multicolumn{2}{|c|}{ \pm 7.4} & \multicolumn{2}{|l|}{ \pm 8} & \multicolumn{2}{|l|}{ \pm 6} \\
\hline & Minimum & \multicolumn{2}{|c|}{26 Minute } & \multicolumn{2}{|c|}{27 Minute } & \multicolumn{2}{|c|}{26 Minute } \\
\hline & Maximum & \multicolumn{2}{|c|}{57 Minute } & \multicolumn{2}{|c|}{57 Minute } & \multicolumn{2}{|c|}{50 Minute } \\
\hline \multirow{4}{*}{ cPRA } & Mean & \multicolumn{2}{|c|}{$21 \%$} & \multicolumn{2}{|c|}{$25 \%$} & $15 \%$ & \\
\hline & SD & \pm 31 & & \pm 34 & & \pm 22 & \\
\hline & Minimum & $0 \%$ & & $0 \%$ & & $0 \%$ & \\
\hline & Maximum & $100^{\circ}$ & & 100 & & $73 \%$ & \\
\hline & Mean & 11 & & 11 & & 11 & \\
\hline & SD & \pm 3.2 & & \pm 3 & & \pm 3 & \\
\hline 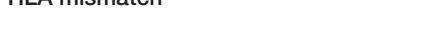 & Minimum & 0 & & 0 & & 2 & \\
\hline & Maximum & 17 & & 17 & & 15 & \\
\hline
\end{tabular}

TABLE 1: Baseline Recipient Characteristics 


\section{Cureus}

BMI: Body Mass Index, cPRA: Calculated Panel Reactive Antibody, ECD: Expanded Criteria of Donor, DCD: Donation after Cardiac Death, ESRD: End-Stage Renal Disease, HLA: Human Leukocyte Antigen, n: Numbers, SD: Standard Deviation.

Donors were mostly of white ethnicity 51 (85\%) with most of them in the ECD and DCD group 23 (95.8\%). Meanwhile, 28 individuals from the donor group were hypertensive compared to only six diabetics.

Regarding the cause of death in the donor groups, cerebrovascular accidents were the most dominant with 38 donors (63.3\%) followed by head trauma 8 (13.3\%), anoxia $6(10 \%)$, other $6(10 \%)$ and central nervous system tumor 2 (3.3\%) (Table 2). The overall mean warm ischemia time in the ECD was $38 \pm 8$ minutes, and the time in the ECD and DCD was almost similar at $38 \pm 6$ minutes. The human leukocyte antigen (HLA)mismatch was identical in both groups with a mean value of $11 \pm 3$. In addition, HLA-DR showed the least match with 0 match in 40 recipients (66.7\%) and only 17 patients had one match (28.3\%), and the HLA-DQ was distributed almost evenly between a 0 match and one match with 28 (46.7\%) and 27 (45\%), respectively. Lastly, the mean value of KDPI in the donor ECD group was $82 \pm 10.5$ and the mean value of the KDPI in the donor ECD and DCD group was $82 \pm 7$ (Table 2). 


\section{Cureus}

\begin{tabular}{|c|c|c|c|c|c|c|c|}
\hline \multicolumn{8}{|c|}{ Baseline Donor Characteristics } \\
\hline \multirow{3}{*}{ Numbers } & & \multicolumn{2}{|l|}{ All } & \multicolumn{2}{|c|}{ ECD } & \multicolumn{2}{|c|}{ ECD and DCD } \\
\hline & & $\mathrm{n}$ & $\%$ & $\mathrm{n}$ & $\%$ & $\mathrm{n}$ & $\%$ \\
\hline & & 60 & $100 \%$ & 36 & 60 & 24 & 40 \\
\hline Age mean $\pm S D$ & & \multicolumn{2}{|c|}{$62 \pm 4.8$} & \multicolumn{2}{|c|}{$62 \pm 5.7$} & \multicolumn{2}{|c|}{$62.5 \pm 3.4$} \\
\hline \multicolumn{2}{|l|}{$\mathrm{BMI}$ mean $\pm \mathrm{SD}$} & \multicolumn{2}{|c|}{$29.4 \pm 6.8$} & \multicolumn{2}{|c|}{$29 \pm 6.9$} & \multicolumn{2}{|c|}{$29.9 \pm 6.9$} \\
\hline \multirow{5}{*}{ Ethnicity } & White & 51 & $85 \%$ & 28 & $77.8 \%$ & 23 & $95.8 \%$ \\
\hline & Asian & 6 & $10 \%$ & 5 & $13.9 \%$ & 1 & $4.2 \%$ \\
\hline & Hispanic & 2 & $3.3 \%$ & 2 & $5.6 \%$ & 0 & $0 \%$ \\
\hline & African American & 1 & $1.7 \%$ & 1 & $2.8 \%$ & 0 & $0 \%$ \\
\hline & Others & 0 & $0 \%$ & 0 & $0 \%$ & 0 & $0 \%$ \\
\hline \multirow{4}{*}{ Hypertension } & $0-5 Y$ & 12 & $20 \%$ & 4 & $11.1 \%$ & 11 & $37.5 \%$ \\
\hline & $6-10 Y$ & 4 & $6.7 \%$ & 4 & $11.1 \%$ & 0 & $0 \%$ \\
\hline & $>10 Y$ & 2 & $3.3 \%$ & 1 & $2.8 \%$ & 1 & $4.2 \%$ \\
\hline & Unknown Duration & 10 & $16.7 \%$ & 8 & $22.2 \%$ & 2 & $8.3 \%$ \\
\hline \multirow{4}{*}{ Diabetes Mellitus } & $0-5 Y$ & 3 & $5 \%$ & 1 & $2.8 \%$ & 2 & $8.4 \%$ \\
\hline & $6-10 Y$ & 2 & $3.3 \%$ & 0 & $0 \%$ & 2 & $8.4 \%$ \\
\hline & $>10 Y$ & 1 & $1.7 \%$ & 1 & $2.8 \%$ & 0 & $0 \%$ \\
\hline & Unknown & 0 & $0 \%$ & 0 & $0 \%$ & 0 & $0 \%$ \\
\hline \multirow{5}{*}{ Cause of Death } & Cerebrovascular Accident & 38 & $63.3 \%$ & 22 & $61.1 \%$ & 16 & $66.7 \%$ \\
\hline & Head Trauma & 8 & $13.3 \%$ & 5 & $13.9 \%$ & 3 & $12.5 \%$ \\
\hline & Anoxia & 6 & $10 \%$ & 3 & $8.3 \%$ & 3 & $12.5 \%$ \\
\hline & Central Nervous System Tumor & 2 & $3.3 \%$ & 2 & $5.6 \%$ & 0 & $0 \%$ \\
\hline & Other & 6 & $10 \%$ & 4 & $11.2 \%$ & 2 & $8.4 \%$ \\
\hline \multirow{2}{*}{ HCV Status } & Negative & 57 & $95 \%$ & 34 & $94.4 \%$ & 23 & $95.8 \%$ \\
\hline & Positive & 3 & $5 \%$ & 2 & $5.6 \%$ & 1 & $4.2 \%$ \\
\hline \multirow{4}{*}{ Serum $\mathrm{Cr}(\mathrm{mmol} / \mathrm{l})$} & Mean & \multicolumn{2}{|l|}{68.7} & \multicolumn{2}{|c|}{73.3} & \multicolumn{2}{|c|}{61.9} \\
\hline & SD & \multicolumn{2}{|c|}{ \pm 24.1} & \multicolumn{2}{|c|}{ \pm 26.6} & \multicolumn{2}{|c|}{ \pm 18.11} \\
\hline & Minimum & \multicolumn{2}{|l|}{33} & \multicolumn{2}{|l|}{33} & \multicolumn{2}{|l|}{34} \\
\hline & Maximum & \multicolumn{2}{|l|}{151} & 151 & & 105 & \\
\hline & Mean & 82 & & 82 & & 86 & \\
\hline & SD & \pm 10 & & \pm 10 & & \pm 7 & \\
\hline & Minimum & 59 & & 59 & & 72 & \\
\hline & Maximum & 97 & & 97 & & 97 & \\
\hline
\end{tabular}

\section{TABLE 2: Baseline Donor Characteristics}

Cr: Creatinine, DCD: Donation after Cardiac Death, ECD: Expanded Criteria of Donor, HCV: Hepatitis C Virus, KDPI: Kidney Donor Profile Index, n: Numbers, SD: Standard Deviation 


\section{Primary outcome}

The mean creatinine value of one month was $183 \pm 112$ in all groups and was the highest among ECD and DCD with a mean value of $211 \pm 71$, and it was lower in the ECD group with a mean value of $165 \pm 131$. The creatinine value of six months showed a decrease in the ECD and DCD group reaching $178 \pm 91$ while it slightly decreased in the ECD group to $171 \pm 117$. Lastly, the creatinine 12 months value in the ECD and DCD decreased further to reach a mean value of $160 \pm 78$. However, in the ECD group, the creatinine 12-month value increased to $185 \pm 206$. Furthermore, the urine protein value showed an overall steady decrease in both groups with one-month, six-month, and 12 -month mean values reported as $32 \pm 74,16 \pm 35$, and $11 \pm 22$, respectively (Table 3). As well, the overall graft loss at 12 months in both groups was $6(10 \%)$ with four from the ECD group and two from the ECD and DCD group. Moreover, only two deaths occurred at the 12 months mark with one death from each group.

\begin{tabular}{|c|c|c|c|c|c|c|c|c|}
\hline \multicolumn{9}{|c|}{ Primary Outcome } \\
\hline & & & \multicolumn{2}{|c|}{ All $(n=60)$} & \multicolumn{2}{|c|}{$\operatorname{ECD}(n=36)$} & \multicolumn{2}{|c|}{ ECD and DCD $(n=24)$} \\
\hline \multicolumn{3}{|c|}{ Cr 1-month (umo/l) Mean \pm SD } & \multicolumn{2}{|c|}{$183 \pm 112$} & \multicolumn{2}{|c|}{$165 \pm 131$} & \multicolumn{2}{|c|}{$211 \pm 71$} \\
\hline \multicolumn{3}{|c|}{ Cr 6-month (umo/l) Mean \pm SD } & \multicolumn{2}{|c|}{$174 \pm 107$} & \multicolumn{2}{|c|}{$171 \pm 117$} & \multicolumn{2}{|c|}{$178 \pm 91$} \\
\hline \multicolumn{3}{|c|}{ Cr 12-month (umo/l) Mean \pm SD } & \multicolumn{2}{|c|}{$175 \pm 167$} & \multicolumn{2}{|c|}{$185 \pm 206$} & \multicolumn{2}{|c|}{$160 \pm 78$} \\
\hline \multicolumn{3}{|c|}{ Urine protein 1-month $\mathrm{mg} / \mathrm{mmol}$ Mean $\pm \mathrm{SD}$} & \multicolumn{2}{|c|}{$32 \pm 74$} & \multicolumn{2}{|c|}{$35 \pm 89$} & \multicolumn{2}{|c|}{$12 \pm 0.7$} \\
\hline \multicolumn{3}{|c|}{ Urine protein 6-month $\mathrm{mg} / \mathrm{mmol}$ Mean $\pm \mathrm{SD}$} & \multicolumn{2}{|c|}{$16 \pm 35$} & \multicolumn{2}{|c|}{$15 \pm 33$} & \multicolumn{2}{|c|}{$18 \pm 39$} \\
\hline \multicolumn{3}{|c|}{ Urine protein 12-month $\mathrm{mg} / \mathrm{mmol}$ Mean $\pm \mathrm{SD}$} & \multicolumn{2}{|c|}{$11 \pm 22$} & \multicolumn{2}{|c|}{$10 \pm 18$} & \multicolumn{2}{|c|}{$2.7 \pm 28$} \\
\hline \multicolumn{3}{|c|}{ LOS Mean \pm SD } & \multicolumn{2}{|c|}{$10 \pm 5$} & $16 \pm$ & & 9.5 & \pm 4 \\
\hline & & & $\mathbf{n}$ & $\%$ & $\mathrm{n}$ & $\%$ & $\mathrm{n}$ & $\%$ \\
\hline & $\mathrm{t}$ loss 12 mont & & 6 & $10 \%$ & 4 & $11 \%$ & 2 & $8.3 \%$ \\
\hline & ent death $12 \mathrm{~m}$ & ionth & 2 & $3.3 \%$ & 1 & $2.8 \%$ & 1 & $4.2 \%$ \\
\hline & lary non functi & on allograft & 3 & $5 \%$ & 3 & $8.3 \%$ & 0 & $0 \%$ \\
\hline $\operatorname{Sec}$ & ondary Outcon & & & & & & & \\
\hline & & & All & & ECD & & EC & $D$ and DCD \\
\hline & & & $\mathrm{n}$ & $\%$ & $\mathrm{n}$ & $\%$ & $\mathrm{n}$ & $\%$ \\
\hline & yed Graft Fun & ction & 20 & $33.3 \%$ & 9 & $25 \%$ & 11 & $45.8 \%$ \\
\hline & Viremia & & 19 & $32 \%$ & 11 & $30.6 \%$ & 8 & $33.3 \%$ \\
\hline & Viremia & & 17 & $28.3 \%$ & 7 & $19.4 \%$ & 10 & $41.7 \%$ \\
\hline & ction in $12 \mathrm{mo}$ & nths & 4 & $6.7 \%$ & 3 & $8.3 \%$ & 2 & $8.3 \%$ \\
\hline & body Mediatec & Rejection & 1 & $1.6 \%$ & 1 & $2.8 \%$ & 0 & $0 \%$ \\
\hline & ell-Mediated R & ejection & 3 & $75 \%$ & 1 & $2.8 \%$ & 2 & $8.3 \%$ \\
\hline & iber of death ir & 12/months Post-Transplant & ents $3.3 \%$ & & & & & \\
\hline & Age/Gender & Cause of ESRD & $\begin{array}{l}\text { Time on } \\
\text { Dialysis }\end{array}$ & $\begin{array}{l}\text { Date of } \\
\text { Transplant }\end{array}$ & $\begin{array}{l}\text { Date of } \\
\text { Death }\end{array}$ & $\begin{array}{l}\text { Time Post- } \\
\text { Transplant }\end{array}$ & & Cause of Death \\
\hline N1 & 79/M & $\begin{array}{l}\text { Focal Segmental } \\
\text { Glomerulosclerosis without } \\
\text { Diabetes }\end{array}$ & 4 years & $16 / 09 / 2018$ & 03/02/2019 & 4 Months & & $\begin{array}{l}\text { Small Bowel Obstruction } \\
\text { /Sepsis }\end{array}$ \\
\hline N2 & 74/M & Diabetic Nephropathy & 5 years & 22/12/2017 & $04 / 02 / 2018$ & 2 Months & & Sepsis/Perforated bowel. \\
\hline Rej & ction Rate: $4 \mathrm{r}$ & atients $6.7 \%$ & & & & & & \\
\hline \# & $\begin{array}{l}\text { Date of } \\
\text { Treatment }\end{array}$ & Date of BPAR & $\begin{array}{l}\text { Type of } \\
\text { Rejection }\end{array}$ & CPRA & $\begin{array}{l}\text { HLA } \\
\text { Mismatch }\end{array}$ & $\begin{array}{l}\text { Type of } \\
\text { Induction }\end{array}$ & & Evidence of non-adherence \\
\hline 1 & $21 / 01 / 2019$ & 03/07/2019 & $\begin{array}{l}\text { Borderline } \\
\text { TCMR }\end{array}$ & $30 \%$ & $\begin{array}{l}\text { 13/18 ODR } \\
1 \mathrm{DQ}\end{array}$ & Thymoglob & & $\begin{array}{l}\text { No, severe } \mathrm{cmv} \text { viremia, refuse } \\
\text { treatment, lost the graft }\end{array}$ \\
\hline
\end{tabular}




\section{Cureus}

\begin{tabular}{|c|c|c|c|c|c|c|c|}
\hline 2 & 09/06/2018 & $14 / 06 / 2019$ & $\begin{array}{l}\text { ABMR no } \\
\text { DSA }\end{array}$ & $78 \%$ & $\begin{array}{l}\text { 11/18 ODQ } \\
\text { ODR }\end{array}$ & Thymoglobulin & No, treated Cr $200 \mathrm{~s}$ \\
\hline 3 & 29/01/2017 & $15 / 11 / 2017$ & $\begin{array}{l}\text { Borderline } \\
\text { TCMR }\end{array}$ & 0 & $\begin{array}{l}\text { 11/18 1DR } \\
\text { 1DQ }\end{array}$ & Basiliximab & $\begin{array}{l}\text { No, CMV pos, medications } \\
\text { reduced, } \mathrm{Cr} 120\end{array}$ \\
\hline 4 & $17 / 12 / 2017$ & $28 / 09 / 2018$ & $\begin{array}{l}\text { Borderline } \\
\text { TCMR }\end{array}$ & 0 & $\begin{array}{l}\text { 7/18 1DQ } \\
\text { 1DR }\end{array}$ & Basiliximab & $\begin{array}{l}\text { No, Tac level 4.4-5.5 BK pos, } \\
\text { treated } \mathrm{Cr} 200 \mathrm{~s}\end{array}$ \\
\hline
\end{tabular}

\section{TABLE 3: Outcomes}

AMBR: Antibody Mediated Rejection, BPAR: Biopsy-Proven Acute Rejection, CMV: Cytomegalovirus, cPRA: Calculated Panel Reactive Antibody, Cr: Creatinine, DCD: Donation after Cardiac Death, DSA: Donor Specific Antibody, ECD: Expanded Criteria of Donor, ESRD: End-Stage Renal Disease, HLA: Human Leukocyte Antigen, LOS: Length of Stay, n: Numbers, SD: Standard Deviation, TCMR: T-Cell Mediated Rejection.

\section{Secondary outcome}

Regarding a secondary outcome, the overall numbers of patients with a delayed graft function were 20 (33\%), nine from the ECD, and 11 from the ECD and DCD group. When comparing CMV and BK viremia, they were almost similar with 19 (32\%) individuals infected with CMV and 17 (28.3\%) reported BK viremia. However, CMV viremia was higher in the ECD group with 11 recorded infections compared to $10 \mathrm{BK}$ viremia cases in the ECD and DCD group. Regarding transplant rejection outcome, only four recipients were reported to have rejection at the 12th month with only one reported antibody-mediated rejection in the ECD, and three had T-cell-mediated rejection (Table 3).

The first reported death at the 12-month period was that of a 79-year-old male who had been on dialysis for four years due to ESRD caused by focal segmental glomerulosclerosis (FSGS) without diabetes. The patients survived four months after his transplant and died due to small bowel obstruction accompanied by sepsis. The second reported case was a 74-year-old male with diabetic neuropathy as the culprit of ESRD. Similarly, he had been on dialysis for five years and passed away two months after the transplant due to small bowel perforation and sepsis (Table 3).

As previously stated, four recipients reported a rejection pattern of 12 months without any reports of nonadherence. The first case was an antibody-mediated rejection type with no donor specific antibody. The patient's calculated panel reactive antibody (CPRA) was 78\% and the HLA mismatch was reported as 11/18 ODQ ODR, and the induction agent of choice was thymoglobulin. The second case, however, was similar except that the rejection pattern was T-cell mediated rejection with cPRA of 30\% and an HLA mismatch of 13/18 0DR 1DQ. Also, the last two cases had basiliximab as an induction agent with no reported cPRA 0\% and a borderline T-cell mediated rejection (Table 3).

Lastly, death censored graft loss was immediate in three cases and was delayed in the fourth one 10 months after the transplant. The first case was a 69 -year-old patient with ESRD caused by urinary tract infection and had a delayed rejection that occurred after 10 months. The main cause of the allograft loss was recurrent CMV viremia and the donor was 69 years old from the ECD group with a KDPI of $86 \%$. The second case was a 78-year-old patient with ESRD caused by hypertension with an immediate rejection of the graft. The main cause of the allograft loss was a primary nonfunctional cause where the donor was 67 years old from the ECD and DCD group with a KDPI of $89 \%$ and was severely atherosclerotic. The third case was that of a 74 -yearold patient with FSGS as the cause of ESRD and immediate rejection. The donor was 66 years old from the ECD group with a KDPI of $95 \%$. Lastly, the final case of a 47-year-old patient with ESRD caused by FSGS who also had an immediate rejection and the donor was 71 years old from the ECD group with a KDPI of 91\% (Table 4). 


\section{Cureus}

\begin{tabular}{|c|c|c|c|c|c|c|c|}
\hline & $\begin{array}{l}\text { Recipient } \\
\text { Age }\end{array}$ & $\begin{array}{l}\text { Cause Of } \\
\text { ESRD }\end{array}$ & $\begin{array}{l}\text { Time from } \\
\text { Transplant }\end{array}$ & Cause of Allograft Loss & $\begin{array}{l}\text { Donor } \\
\text { Age }\end{array}$ & $\begin{array}{l}\text { Type of } \\
\text { Donor }\end{array}$ & KDPI \\
\hline $\begin{array}{l}\text { Case } \\
1\end{array}$ & $69 \mathrm{Y}$ & UTls & 10 month & $\begin{array}{l}\text { Recurrent CMV viremia, TCMR and } \\
\text { immunosuppression intolerance }\end{array}$ & $64 \mathrm{Y}$ & ECD & $86 \%$ \\
\hline $\begin{array}{l}\text { Case } \\
2\end{array}$ & $78 Y$ & HTN & Immediate & $\begin{array}{l}\text { Primary non function (severe atherosclerotic donor } \\
\text { kidney) }\end{array}$ & $67 \mathrm{Y}$ & ECD/DCD & $89 \%$ \\
\hline $\begin{array}{l}\text { Case } \\
3\end{array}$ & $74 \mathrm{Y}$ & FSGS & Immediate & Primary non function (TMA) & $66 \mathrm{Y}$ & ECD & $95 \%$ \\
\hline $\begin{array}{l}\text { Case } \\
4\end{array}$ & $42 Y$ & FSGS & Immediate & Primary non function (recurrent FSGS) & $71 \mathrm{Y}$ & ECD & $91 \%$ \\
\hline
\end{tabular}

\section{TABLE 4: Death Censored Graft Loss}

CMV: Cytomegalovirus, DCD: Donation after Cardiac Death, ECD: Expanded Criteria of Donor, ERSD: End-Stage Renal Disease, FSGS: Focal Segmental Glomerulosclerosis, HTN: Hypertension, KDPI: Kidney Donor Profile Index, TCMR: T-Cell Mediated Rejection, TMA: Thrombotic Microangiopathy, UTIs: Urinary Tract Infections.

\section{Discussion}

The growing gap between demand and supply for kidney transplants leads to renewed interest in the use of ECD kidneys to increase the donor pool. In Canada, kidneys from deceased donors makes up approximately $60 \%$ of the donor pool over the last decade [12]. Although most studies of ECD kidney transplantation confirm lower allograft survival rates and, generally, worse outcomes than SCD kidneys, recipients of ECD kidneys generally have improved survivability in comparison to the wait-listed dialysis patients, thus encouraging the pursuit of this type of kidney transplantation [5]. Our study is the first study that considers the outcome of kidney transplantation using the ECD kidneys at St. Joseph Hospital in Hamilton. Our results show a favorable outcome comparable with Canadian outcomes [13].

According to Young et al., total graft loss was $10 \%$ vs $11.4 \%$ in the first-year post transplantations [13]. In comparison, death censored graft loss is $6.9 \%$ vs $6.6 \%$ in our data. According to Wu WK et al., the risk of DGF was more likely to occur in male and older donors and is similar to our findings where all rejections occur from donors above the age of 70 years [14]. Descriptively, the survival rate in the first year posttransplantation patients is $97 \%$ when compared to the literature of the United States and Canada with $>90 \%$ survival rate $[15,16]$. So, it appears that the utilization of extended criteria donor kidneys can significantly improve survival for older recipients, and we should encourage using these ECD kidneys for the appropriate matching ages. The limitations of our study were a small patient sample and short term follow up. We did not include the outcome of kidney transplantation using SCD in our center as a comparable group. Furthermore, the data was not statistically analyzed to do so once a larger sample size was collected and followed up over the coming years. Our future direction is to follow-up with the recipients over a three- to five-year period and compare the survival and graft function to SCD donors at our center. Moreover, we will calculate the cold ischemic time, and donor KDPI and correlate it with the actual recipient outcome.

\section{Conclusions}

Descriptive data of renal transplantation recipients with ECD kidneys at St. Joseph Hospital resulted in initial favorable outcomes when compared with other programs in Canada as well as global programs. The use of these organs should continue to be more widely considered given the high morbidity and mortality experienced by patients on dialysis.

\section{Additional Information \\ Disclosures}

Human subjects: Consent was obtained by all participants in this study. Hamilton Research Ethics Board issued approval HIREB. The research was approved by the Institutional Review Board of Hamilton Research Ethics Board in Hamilton, Canada and all information collected after obtaining of a verbal consent from all participants. Animal subjects: All authors have confirmed that this study did not involve animal subjects or tissue. Conflicts of interest: In compliance with the ICMJE uniform disclosure form, all authors declare the following: Payment/services info: All authors have declared that no financial support was received from any organization for the submitted work. Financial relationships: All authors have declared that they have no financial relationships at present or within the previous three years with any organizations that might have an interest in the submitted work. Other relationships: All authors have declared that there are no other relationships or activities that could appear to have influenced the submitted work. 


\section{Acknowledgements}

The authors would like to give our appreciation and thanks to Dr Christine Ribic, without her constant support, guidance and supervision, this manuscript wouldn't be possible.

\section{References}

1. Nathan HM, Conrad SL, Held PJ, et al.: Organ donation in the United States. Am J Transplant. 2003, 3:29-40. 10.1034/j.1600-6143.3.s4.4.x

2. Tonelli M, Wiebe N, Knoll G, et al.: Systematic review: kidney transplantation compared with dialysis in clinically relevant outcomes. Am J Transplant. 2011, 11:2093-109. 10.1111/j.1600-6143.2011.03686.x

3. Wolfe RA, Ashby VB, Milford EL, et al.: Comparison of mortality in all patients on dialysis, patients on dialysis awaiting transplantation, and recipients of a first cadaveric transplant. N Engl J Med. 1999, 341:1725-30. 10.1056/NEJM199912023412303

4. Wolfe RA, Roys EC, Merion RM: Trends in organ donation and transplantation in the United States, 19992008. Am J Transplant. 2010, 10:961-72. 10.1111/j.1600-6143.2010.03021.x

5. Metzger RA, Delmonico FL, Feng S, Port FK, Wynn JJ, Merion RM: Expanded criteria donors for kidney transplantation. Am J Transplant. 2003, 3:114-25. 10.1034/j.1600-6143.3.s4.11.x

6. Filiopoulos V, Boletis JN: Renal transplantation with expanded criteria donors: which is the optimal immunosuppression?. World J Transplant. 2016, 6:103-14. 10.5500/wjt.v6.i1.103

7. Waiser J, Budde K, Böhler T, Neumayer HH: The influence of age on outcome after renal transplantation . Geriatr Nephrol Urol. 1997, 7:137-46. 10.1023/A:1008263727499

8. Doyle SE, Matas AJ, Gillingham K, Rosenberg ME: Predicting clinical outcome in the elderly renal transplant recipient. Kidney Int. 2000, 57:2144-50. 10.1046/j.1523-1755.2000.00066.x

9. Dayoub JC, Cortese F, Anžič A, Grum T, de Magalhães JP: The effects of donor age on organ transplants: a review and implications for aging research. Exp Gerontol. 2018, 110:230-40. 10.1016/j.exger.2018.06.019

10. Lee JH, Park WY, Kim YS, et al.: Clinical significance of the Kidney Donor Profile Index in deceased donors for prediction of post-transplant clinical outcomes: a multicenter cohort study. PLoS One. 2018, 13:e0205011. 10.1371/journal.pone.0205011

11. Bae S, Massie AB, Luo X, Anjum S, Desai NM, Segev DL: Changes in discard rate after the introduction of the Kidney Donor Profile Index (KDPI). Am J Transplant. 2016, 16:2202-7. 10.1111/ajt.13769

12. Moist LM, Fenton S, Kim JS, et al.: Canadian Organ Replacement Register (CORR): reflecting the past and embracing the future. Can J Kidney Health Dis. 2014, 10.1186/s40697-014-0026-5

13. Young A, Dixon SN, Knoll GA, et al.: The Canadian experience using the expanded criteria donor classification for allocating deceased donor kidneys for transplantation. Can J Kidney Health Dis. 2016, 10.1186/s40697-016-0106-9

14. Wu WK, Famure O, Li Y, Kim SJ: Delayed graft function and the risk of acute rejection in the modern era of kidney transplantation. Kidney Int. 2015, 88:851-8. 10.1038/ki.2015.190

15. Wang JH, Skeans MA, Israni AK: Current status of kidney transplant outcomes: dying to survive . Adv Chronic Kidney Dis. 2016, 23:281-6. 10.1053/j.ackd.2016.07.001

16. Knoll G, Cockfield S, Blydt-Hansen T, et al.: Canadian Society of Transplantation: consensus guidelines on eligibility for kidney transplantation. Can Med Assoc J. 2005, 173:S1-S25. 10.1503/cmaj.1041588 